NASA/TM-2007-214985

ARL-TR-4202
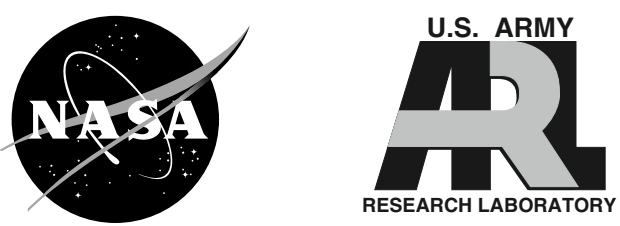

AIAA-2007-5049

\title{
Comparison Between Simulated and Experimentally Measured Performance of a Four Port Wave Rotor
}

Daniel E. Paxson

Glenn Research Center, Cleveland, Ohio

Jack Wilson

ASRC Aerospace, Cleveland, Ohio

Gerard E. Welch

U.S. Army Research Laboratory, Cleveland, Ohio 


\section{NASA STI Program . . . in Profile}

Since its founding, NASA has been dedicated to the advancement of aeronautics and space science. The NASA Scientific and Technical Information (STI) program plays a key part in helping NASA maintain this important role.

The NASA STI Program operates under the auspices of the Agency Chief Information Officer. It collects, organizes, provides for archiving, and disseminates NASA's STI. The NASA STI program provides access to the NASA Aeronautics and Space Database and its public interface, the NASA Technical Reports Server, thus providing one of the largest collections of aeronautical and space science STI in the world. Results are published in both non-NASA channels and by NASA in the NASA STI Report Series, which includes the following report types:

- TECHNICAL PUBLICATION. Reports of completed research or a major significant phase of research that present the results of NASA programs and include extensive data or theoretical analysis. Includes compilations of significant scientific and technical data and information deemed to be of continuing reference value. NASA counterpart of peer-reviewed formal professional papers but has less stringent limitations on manuscript length and extent of graphic presentations.

- TECHNICAL MEMORANDUM. Scientific and technical findings that are preliminary or of specialized interest, e.g., quick release reports, working papers, and bibliographies that contain minimal annotation. Does not contain extensive analysis.

- CONTRACTOR REPORT. Scientific and technical findings by NASA-sponsored contractors and grantees.
- CONFERENCE PUBLICATION. Collected papers from scientific and technical conferences, symposia, seminars, or other meetings sponsored or cosponsored by NASA.

- SPECIAL PUBLICATION. Scientific, technical, or historical information from NASA programs, projects, and missions, often concerned with subjects having substantial public interest.

- TECHNICAL TRANSLATION. Englishlanguage translations of foreign scientific and technical material pertinent to NASA's mission.

Specialized services also include creating custom thesauri, building customized databases, organizing and publishing research results.

For more information about the NASA STI program, see the following:

- Access the NASA STI program home page at http://www.sti.nasa.gov

- E-mail your question via the Internet to help@sti.nasa.gov

- Fax your question to the NASA STI Help Desk at 301-621-0134

- Telephone the NASA STI Help Desk at 301-621-0390

- Write to: NASA Center for AeroSpace Information (CASI) 7115 Standard Drive Hanover, MD 21076-1320 
NASA/TM-2007-214985

ARL-TR-4202
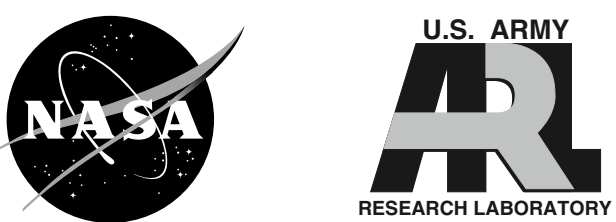

AIAA-2007-5049

\section{Comparison Between Simulated and Experimentally Measured Performance of a Four Port Wave Rotor}

Daniel E. Paxson

Glenn Research Center, Cleveland, Ohio

Jack Wilson

ASRC Aerospace, Cleveland, Ohio

Gerard E. Welch

U.S. Army Research Laboratory, Cleveland, Ohio

Prepared for the

43rd Joint Propulsion Conference

sponsored by the American Institute of Aeronautics and Astronautics

Cincinnati, Ohio, July 8-11, 2007

National Aeronautics and

Space Administration

Glenn Research Center

Cleveland, Ohio 44135 


\section{Acknowledgments}

Many people contributed to a project of this scope. We are grateful to them all for their services rendered at one point in time or another. However, the efforts of Thomas Jett, Richard Senyitko, Cleve Horn III, Paulette Adams, Carlos Gomez, and Robert Pastel in the test cell, and the design teams under Laura Stokely, and later Paul Solano, deserve special recognition. Financial support was provided most recently through the NASA Constant Volume Combustion Cycle Engine Project, under the direction of Leo Burkardt. We are appreciative of his foresight, and enthusiasm. The same must be said of the late Dr. Lawrence Bober, who initiated wave rotor research at NASA Glenn many years ago, while serving as Chief of the Turbomachinery Technology Branch.

This report is a formal draft or working paper, intended to solicit comments and ideas from a technical peer group.

This report contains preliminary findings, subject to revision as analysis proceeds.

This work was sponsored by the Fundamental Aeronautics Program at the NASA Glenn Research Center.

Level of Review: This material has been technically reviewed by technical management.

Available from

NASA Center for Aerospace Information 7115 Standard Drive

Hanover, MD 21076-1320
National Technical Information Service 5285 Port Royal Road Springfield, VA 22161 


\title{
Comparison Between Simulated and Experimentally Measured Performance of a Four Port Wave Rotor
}

\author{
Daniel E. Paxson \\ National Aeronautics and Space Administration \\ Glenn Research Center \\ Cleveland, Ohio 44135 \\ Jack Wilson \\ ASRC Aerospace \\ Cleveland, Ohio 44135 \\ Gerard E. Welch \\ U. S. Army Research Laboratory \\ Glenn Research Center \\ Cleveland, Ohio 44135
}

\begin{abstract}
Performance and operability testing has been completed on a laboratory-scale, four-port wave rotor, of the type suitable for use as a topping cycle on a gas turbine engine. Many design aspects, and performance estimates for the wave rotor were determined using a time-accurate, one-dimensional, computational fluid dynamics-based simulation code developed specifically for wave rotors. The code follows a single rotor passage as it moves past the various ports, which in this reference frame become boundary conditions. This paper compares wave rotor performance predicted with the code to that measured during laboratory testing. Both on and off-design operating conditions were examined. Overall, the match between code and rig was found to be quite good. At operating points where there were disparities, the assumption of larger than expected internal leakage rates successfully realigned code predictions and laboratory measurements. Possible mechanisms for such leakage rates are discussed.
\end{abstract}

\section{Nomenclature}

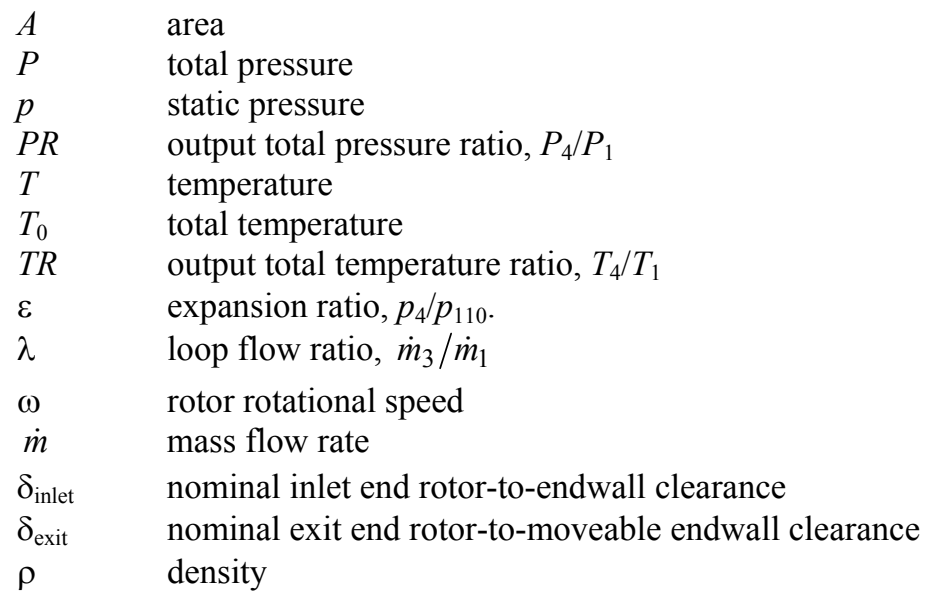

\section{Subscripts}

$1 \quad$ Port 1

2 Port 2

3 Port 3

4 Port 4

110 passage location just prior to entering Port 4 


\section{Introduction}

Wave rotors have been under investigation at the NASA Glenn Research Center (GRC) and other organizations for a number of years. Although many potential applications for these devices exist, the primary focus at NASA has been in their use as topping cycles for gas turbine engines. The thermodynamic benefits of such an application, and the basic principles of operation have been developed extensively in the literature (e.g., refs. 1and 2). Briefly however, the wave rotor for this application consists of a series of passages of constant trapezoidal cross-section, arranged circumferentially about, at some fixed radial distance from, and aligned with, an axis of rotation. This is shown schematically in figure 1 . The passages rotate on a central shaft (with hubs) and are surrounded by a casing. At the ends of the casing, and perpendicular to the passage ends, are stationary plates with slots located at various circumferential positions. The slots, which are the same height as the passages, comprise the ports through which the working fluid either enters or leaves the rotor. The primary purpose of the rotor rotation is to cyclically expose each passage to the various ports (i.e., timing), thus creating the unsteady waves by which the device operates. The waves do work on, or extract work from, the fluid through which they propagate, thereby effecting a complete thermodynamic cycle in the course of passage rotation. The process in any single passage is unsteady, but periodic. The flows in the ports however, are nominally steady, though circumferentially non-uniform. For the device shown in figure 1, Ports 1 and 2 constitute the compression portion of the cycle, while Ports 3 and 4 constitute the expansion portion. The work done on the compressed flow balances that done by the expanded flow. A detailed view of the gas dynamic cycle is presented later in Section IV.

For this four-port, through-flow style cycle, the average total pressure of the outflow from Port 4 is higher than that of the inflow to Port 1. The total enthalpy of Port 4 is also above that of Port 1 due to the addition of heat in the combustor loop. The combustor loop consists of the outflow from Port 2 to a heat addition device (not shown), and the inflow to Port 3 from the heat addition device. The average output pressure ratio achieved, $P R=P_{4} / P_{1}$ measured against the amount of heat added, or alternately, the mass-averaged temperature ratio, $T R=T_{4} / T_{1}$ is the primary figure of merit for this type of cycle. Wave rotor-topped gas turbines derive their thermodynamic benefit from $P R$ : larger values yield higher engine cycle efficiencies. It is noted however, that because this figure of merit involves an averaged total pressure from a spatially non-uniform flow, the manner in which the average is obtained is of some consequence. The methodology used in this paper is described, albeit briefly, in Section IV.

In an effort to test the performance and operability of the concept just described, an experimental four port wave rotor, very similar to figure 1, was fabricated and installed at the GRC. A photograph of the assembled, highly instrumented rig is shown in figure 2. Substantial testing was performed in 2005 and 2006. Details of the unit and test results may be found in references 3 to 5 .

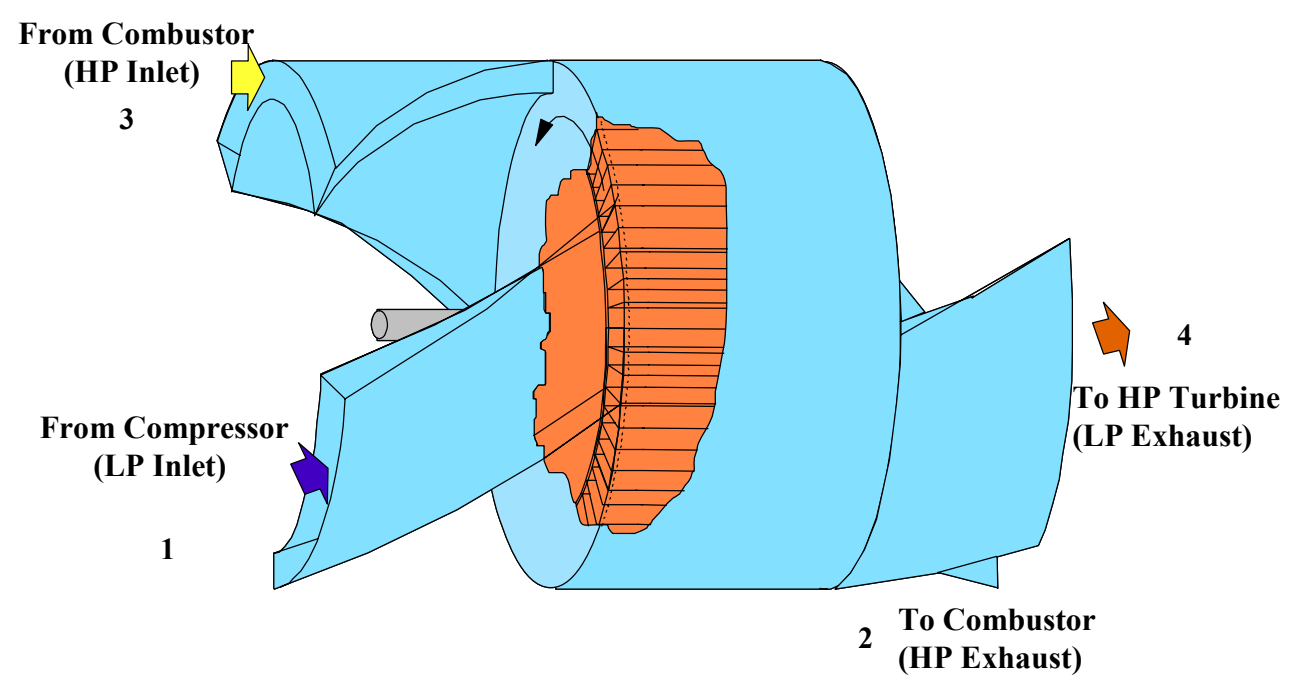

Figure 1.-Four-port, through-flow wave rotor schematic. 


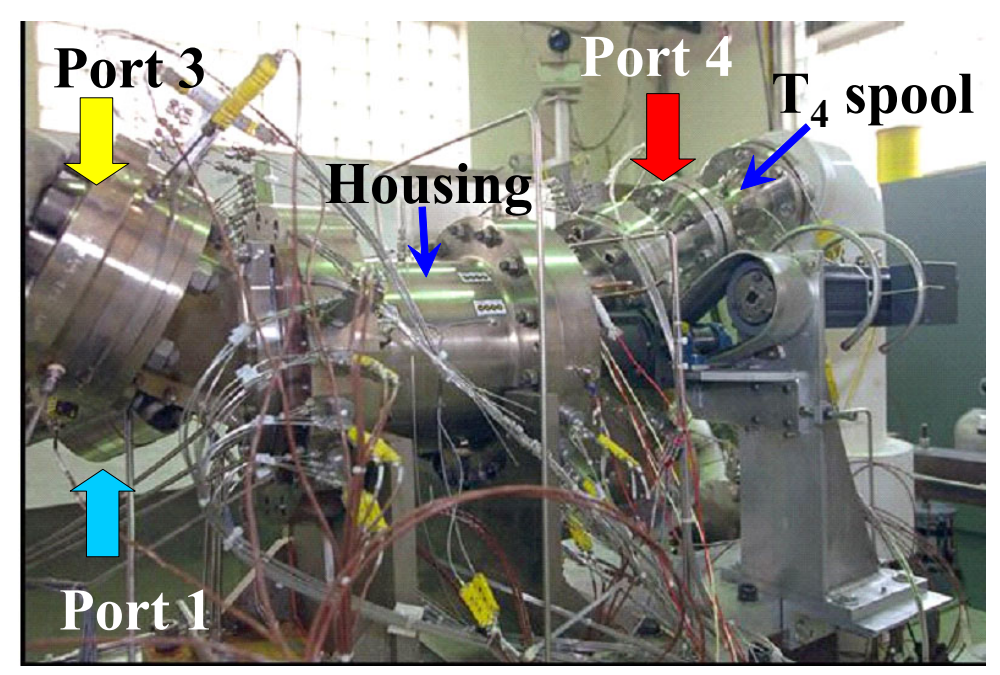

Figure 2.-Assembled NASA four-port wave rotor.

Many aspects of the rig design were determined using a one-dimensional, computational fluid dynamic (CFD) simulation code developed at GRC (refs. 6 to 10) specifically for wave rotor analyses. These aspects include the port sizes, placement, and duct flow angles, and the rotor dimensions (length, radius, and passage width). Port flow rates, pressures, and gas and wall temperatures were also estimated with the code. These were used in conjunction with other analysis packages to determine material selection, cooling needs, etc. and to perform heat and stress load analyses on the rotor and endwalls. The "design point" was also obtained with the code. The original design operating point was determined by finding the expansion ratio which, at the specified design temperature ratio, yielded the highest output pressure ratio. The expansion ratio, $\varepsilon$, is the ratio of the mean static pressure in Port 4 of figure 1, to the average pressure in a passage just before it is exposed to Port 4 . This is a somewhat obscure parameter to measure in an experiment; however, provision was made to do so in the NASA Glenn rig.

Along with design parameter selection, the code was used to estimate the wave rotor performance across the estimated operating range. This paper presents a comparison between these estimates and measurements made in the laboratory. The comparison will be made over a range of variation in operating parameters. That is, both on and offdesign operation will be considered. Both averaged and discrete probe data will be examined.

The value of such comparison is two-fold. First, where code and experiment match well, there is increased confidence in the validity of both. Simulation of other wave rotor designs can then proceed with greater assurance that the physical unit will perform as predicted. Meanwhile, the rig results, which in this case involved literally hundreds of measurements on different parts of the wave rotor, can be read with increased confidence that all instruments were installed correctly. Furthermore, the validated code can shed light on the fluidic mechanisms behind the performance trends observed. The second value of comparison arises when the measured and simulated data disagree. With detailed analysis of data it may be possible to ascertain whether there are shortcomings to the simulation, or anomalous behavior of the rig. An example of what appears to be the latter will be illustrated in the discussion of an internal leakage issue which could not be detected by available instrumentation. For the most part however, it will be shown that, without tuning of the code parameters, substantial agreement between code and measurement was achieved.

Since the code has been adequately described in the literature, only a brief functional outline will be presented here. Similarly, since many details of the experiment have been published previously, only those relevant to the comparisons will be shown. The main body of the paper will commence with these descriptions. From there the comparisons will be presented for selected operating points. Concluding remarks will follow.

\section{Code Description}

The code is a time accurate, quasi-one-dimensional simulation which numerically integrates the equations of mass, momentum, and energy for a calorically perfect gas, in a single passage of the wave rotor, as it rotates past the various ports governing the cycle. A second order, Lax-Wendroff integration scheme is utilized which incorporates Roe's approximate Riemann solver and a flux limiter in order to ensure total variation diminishing behavior, while 
preserving sharp resolution of shock waves and contact discontinuities. Source terms have been added to account for the effects of leakage between the passage and the casing, wall friction, and wall-to-gas heat transfer. The submodels which comprise the source terms have been developed using results from previous wave rotor experiments. They contain correlations which link their relative strength to physical aspects of the experimental rig (e.g., rotor-toendwall clearances, passage hydraulic diameter, Prandtl number), and local fluid variables such as velocity and density. Source terms are applied globally to those modeling wall friction and heat transfer effects. They are applied discretely in the first and last interior numerical cell for leakage effects. Additionally, the code has provision for diffusion terms; however, they were not utilized here.

A robust, characteristics-based boundary condition algorithm has been developed which permits inflow or outflow at any port, depending on the status of the passage flow and the specified port pressures. This allows simulation of both on and off-design operation. Inflow losses due to incidence, and gradual opening and closing (i.e., throttling of the passage as it rotates into or out of a port region) are accounted for using sub-models. The code operates in the passage relative frame, while boundary conditions are specified in the absolute frame. The boundary conditions routines account for this reference frame change as well. When the passage is adjacent to a solid wall, a separate boundary routine is applied which ensures that the flux quantities at the passage end face are zero. The temporal specification of boundary conditions (i.e., which to apply, and when) is determined by the user specified location of the ports, and the rotor speed.

In order to obtain meaningful limit cycle results with which to compare experimental results, two components have been added to the code. Shown schematically in figure 3, the first is a simple cavity representing the casing volume not occupied by the rotor. Internal leakage flow travels to and from this volume (via the code source terms) as the passage rotates. The amount and direction of leakage depends on the state of the cavity, and the state of the passage cells where leakage is assumed to occur. The gas state in the cavity is updated each revolution, or cycle, of the rotor. The updating is done via simple Euler integration with a time step equal to the period of one cycle. The integration is not time-accurate, but does not need to be since it is merely used to achieve a steady state result. When the net flow to the cavity over the course of a cycle is zero, convergence has been reached, and the cavity gas state no longer changes.

The second additional component is a burner model which links Ports 2 and 3. It is again modeled as a simple cavity; however, a heat addition term and a total pressure loss term are added. The cavity state is governed by the computed flows from Port 2, and to Port 3, as well as by the specified heat addition rate. The state is updated each cycle, again via first order time integration. When the flow into the burner matches the flow out, and the burner state is unchanged from one cycle to the next, convergence has been reached.

Since the code contains a heat transfer model, the rotor wall temperature must be supplied at each numerical cell. Initially, this is chosen as the inlet temperature. The code then computes through one wave cycle (rotor revolution) integrating the total heat flux into or out of the wall at each cell. The heat flux is assumed to occur between the rotor wall and the working fluid and, to a much lesser extent, between the rotor wall and the internal leakage cavity fluid.

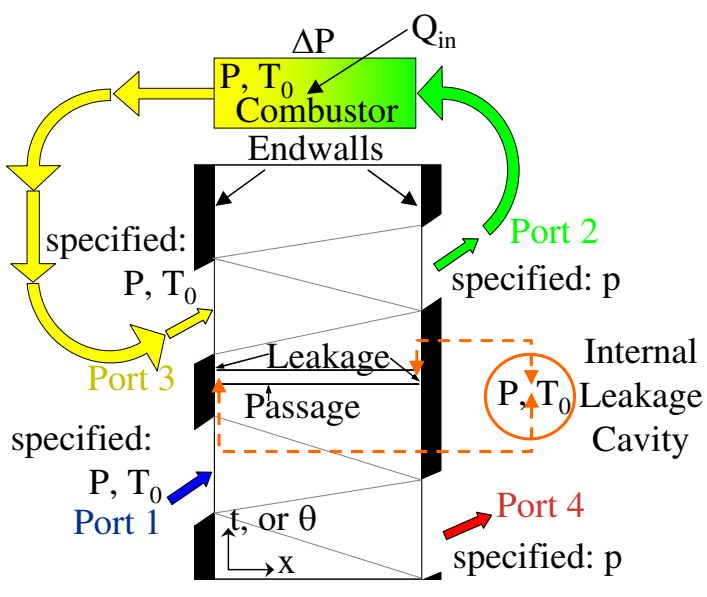

Figure 3.-Simulation component schematic. 
The rotor housing is assumed adiabatic. At the end of the cycle, the wall temperatures are updated, lumped parameter style, using an arbitrary thermal mass, a first order Euler scheme, and the integrated heat flux. This process is repeated until the wall temperatures stop changing.

For the results presented in this paper, unless otherwise stated, the following methodology is used to simulate a given experimental operating point. Endwall-to-rotor clearances are assumed to be 0.004 in. at the inlet end and 0.002 in. at the exhaust end. These correspond to the measured values when the wave rotor was assembled. Boundary conditions are imposed in different ways for different ports. The measured stagnation pressure and temperature are specified for Port 1. Constant static pressure is imposed for Port 4. It is adjusted until the computed inlet flow rate matches the experimentally measured value plus approximately $8 \%$ to account for blockage due to the finite thickness of the passage side walls. Total conditions for port 3 and static pressure for port 2 are supplied by the burner component model. The heat addition term and the total pressure loss terms are adjusted until the computed and measured values of $T R$ and the so-called loop flow ratio match. Loop flow ratio, $\lambda$, is the ratio of the mass flow rate in Port 3 to that in Port 1. Adjustment of the combustor pressure loss term, which is normally proportional to the square of the mass flow rate, was necessary due to the unique arrangement of the experimental rig. This will be described in the next section. Port mass flow rates are determined in the simulation by integration of total mass flowing into or out of the passage ends during the time period that the passage is exposed to a given port. The integrated quantity is then divided by the total port exposure time.

\section{Rig Description}

A scaled drawing of the rotor and housing is shown in figure 4. This is an 'unwrapped' view taken at passage mid-span. Also shown are the locations of instrumentation. A key to the instrumentation is shown in the upper right corner of the figure. The port static pressure locations shown are correct circumferentially; however, they have been shifted axially for clarity. Their actual axial location coincided with the measurement plane of the rakes. For each circumferential location there were static taps located in the hub and tip port walls. The rakes were oriented radially and for all but one contained alternating total pressure and temperature taps ( 3 pressure, 2 temperature) spaced to cover the passage span. Unfortunately, not all of the instrumentation shown was available during all of the testing. The downstream rakes of Port 4 were not in place until the most recent series of tests (ref. 5). The dynamic transducers and wall taps were only available during initial testing.

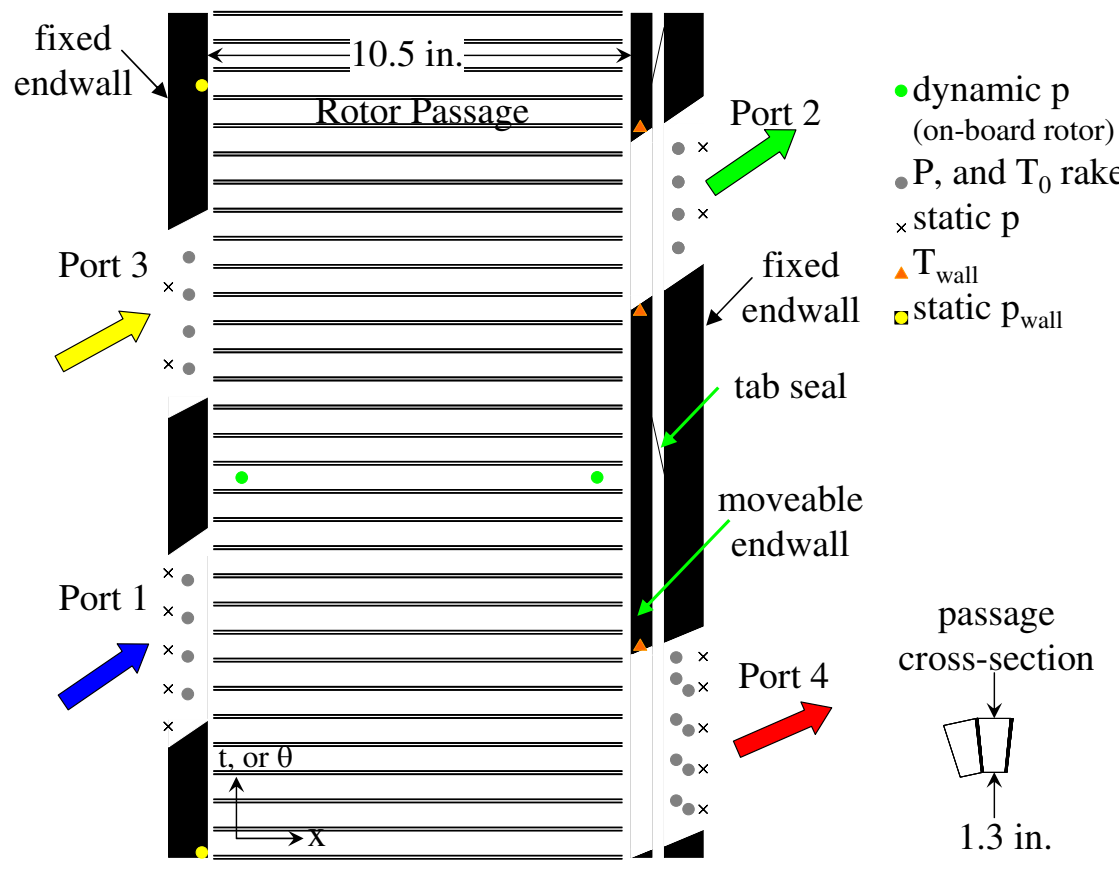

Figure 4.- Scaled rotor and endwall layout, and instrumentation locations. 
Also shown in figure 4 is a component referred to as a moveable endwall. This was a critical component in testing and performance and therefore deserves some explanation. A more detailed explanation is available in reference 3. The spacing between the inlet end of the rotor and the adjacent housing is fixed via a precision ball bearing set on the rotor shaft. The spacing between the outlet end of the rotor and the moveable endwall is similarly fixed. The moveable endwall can translate axially relative to the fixed outlet endwall. It does so against the action of a spring (not shown) mounted between it and the fixed endwall. The idea behind this arrangement is to allow for axial thermal expansion of the rotor while maintaining small rotor-to-endwall clearances. It is clear from figure 4 however, that this arrangement creates a new potential leakage path in the gap between the moveable and fixed endwalls. The gap shown has been exaggerated to highlight the path. The actual gap was approximately $0.065 \mathrm{in}$. Leakage through this gap can be driven by the difference between the high pressure air in Port 2 and the low pressure air in Port 4. In order for the moveable endwall to be effective, this gap must be sealed. This was accomplished, in principle, using tab seals as shown in figure 4 . The tab seals are spring loaded vanes which are attached to the fixed endwall, and which press against the moveable endwall. Their orientation is such that a pressure difference across them augments the spring force acting on the free end.

This wave rotor rig was fitted with an electric heater rather than a combustor to supply heat to the system. The large total pressure losses associated with the heater precluded closed loop operation. Instead, the compressed air from Port 2 that would have fed the heater was ducted to the facility altitude exhaust system through a controlled valve. A separate, high pressure facility air supply line fed the heater, also through a controlled valve. Air from the heater was then ducted to Port 3 . Both the Port 2 and Port 3 ducts were equipped with calibrated flow meters. During operation of the wave rotor, the control valves were continually adjusted to insure that the mass flows matched each other, and provided the desired loop flow rate, thereby simulating a closed combustor loop.

One important component, not shown in figure 4, is a spool located in the Port 4 duct, approximately 18 in. downstream from the rotor. It is visible in the upper right corner of figure 2 . The spool contained a series of spatially distributed thermocouples which were averaged to produce a single measurement representing the Port 4 massaveraged total temperature.

\section{Design Point and Performance Estimates}

The computed design point cycle is shown in figure 5. Here the rotor and port layout of figure 4 has been overlayed with computed contours of pressure and temperature in the passage as it moves past the ports. The expansion ratio of this cycle is 0.4 . The mass averaged output temperature ratio is 2.0 by design. The computed inlet flow rate is $0.73 \mathrm{lb} / \mathrm{m}$. The loop flow ratio is 1.57 . The average output total pressure ratio is 1.13 . A constant area mixing calculation (ref. 11) is used to obtain the average total pressure in Port 4. Integrated fluxes of mass, momentum, and energy used for such a calculation are supplied from the code boundary cells. The design inlet total temperature and pressure were $400 \mathrm{R}$ and 7.5 psia respectively. These low values were chosen in order to avoid extremely high temperatures and pressures on board the rotor or in the ducts. They are not representative of a gas turbine topping cycle environment; however, the output total temperature ratio is. The port flow angles were chosen such that the mean flows in the ports were aligned with the rotor passages in the rotor relative reference frame.

Examination of the contours in figure 5 reveals the motivation for the placement and extent of the ports. It is evident that the waves are terminated, initiated, and reflected at the leading and trailing edges of the ports. Throughflow cycles such as this one cannot be designed without some spurious (i.e., unwanted) waves remaining in the cycle. One such wave, a shock, is seen to be initiated at the trailing edge of Port 2. It travels upstream, reflects off of the inlet endwall, and then travels downstream to reflect off of the constant pressure surface of Port 4 . As will be seen in Section VI, this reflection generates additional non-uniformities in the already non-uniform Port 4 flowfield. Non-uniformities are undesirable as they negatively impact downstream turbomachinery if unmixed, and generate entropy if they are mixed.

The temperature contour of figure 5 illustrates an interesting feature of four-port, through-flow cycles that will also be relevant to Section VI. It can be seen that not all of the hot flow introduced to the passage in Port 3 leaves through Port 4. A significant portion remains in the passage and is discharged into Port 2 along with the cold gas ingested from Port 1. This results in a highly stratified Port 2 flowfield. In fact, it is Port2, not Port3 where the highest local temperatures are seen. It also results in the flow rates of Ports 2 and 3 being different from those of Ports 1 and 4. Simulations of other four-port, through-flow wave rotor cycles have indicated that, in topping cycle configurations, with surrounding turbomachinery, over an engine throttle line, the wave rotor operates with constant corrected inlet flow, and near constant corrected speed. The combustor loop flow varies; however, the combustor loop total pressure drop divided by the square of the mass flow rate (i.e., the loss coefficient) stays nearly constant. This is the combustor loss model implemented in the code. With the inlet flow rate and rotor speed fixed therefore, 


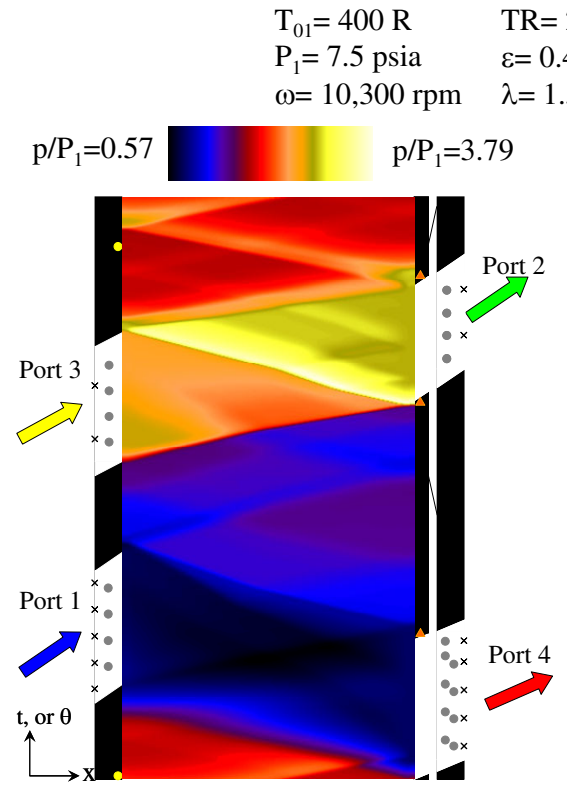

(a)
$\mathrm{PR}=1.13$

$\dot{m}_{1}=0.73 \mathrm{lb}_{\mathrm{m}} / \mathrm{s}$

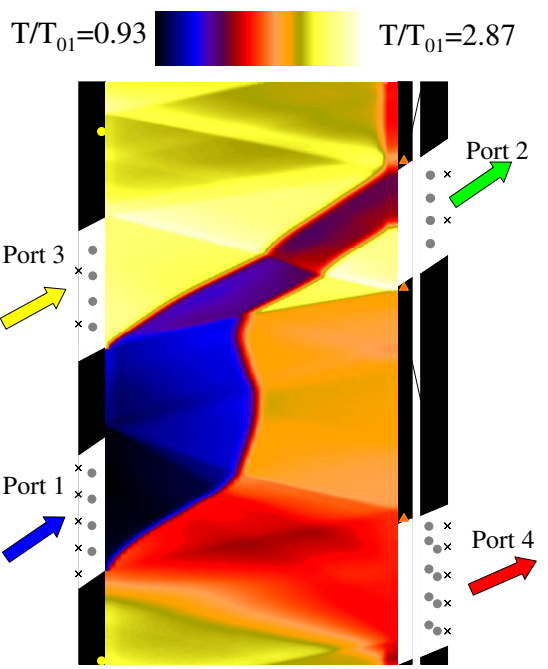

(b)

Figure 5.-Computed contours of (a) pressure, and (b) temperature for the design operating point of the NASA 4-Port Wave Rotor.

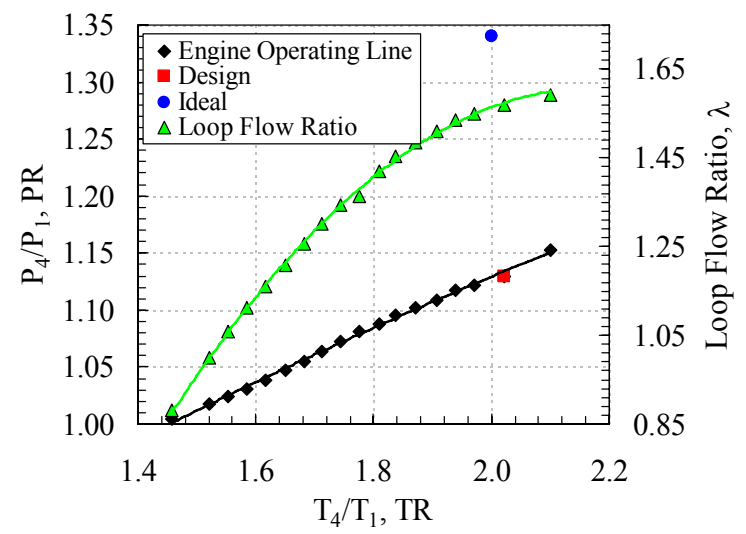

Figure 6.-Predicted performance of the NASA 4-Port

Wave Rotor. The mass flow rate, total temperature and total pressure of Port 1 are $0.73 \mathrm{lb}_{\mathrm{m}} / \mathrm{s}, 400 \mathrm{R}$, and 7.5 psia respectively. The rotor speed is $10,300 \mathrm{rpm}$.

along with the combustor loss coefficient, the simulation was run through different heat addition levels to obtain a performance estimate over a relevant operating range representing idle to maximum throttle. The results are shown in figure 6 in the form of $P R$ as a function of $T R$. Also shown is the predicted loop flow ratio through the same throttle line. For reference, the ideal output pressure ratio is shown corresponding to a temperature ratio of 2.0 . This is the performance predicted by the simulation with all of the loss models disabled. The only losses are therefore those associated with shock waves, and with constant area mixing of non-uniform flows. Evidently, the inherent losses of the machine can be quite significant. This underscores the need to account for them in order to adequately assess the benefits of any wave rotor application. On the other hand, it should be borne in mind that this particular experiment had unusually high viscous losses due to its operation at sub-atmospheric inlet pressures (i.e., low density) which would not be the case for a wave rotor in a topping cycle (ref. 2). 


\section{Initial Results: 1999}

There were numerous difficulties associated with initial operation of the wave rotor rig. Furthermore, the performance was considerably below expectation. However, the early results represent the only period during which nearly all of instrumentation was functional. They are therefore worth examining from the standpoint of code validation. As such, two early operating points will be compared to the code.

\section{A. Case 1: Near-Design Point}

The first case represents the design temperature ratio, but a somewhat higher rotor speed and loop flow ratio, and at a lower inlet mass flow rate. The relevant parameters are listed in table 1.

\begin{tabular}{|c|}
\hline$\omega, \mathrm{rpm}$ \\
\hline 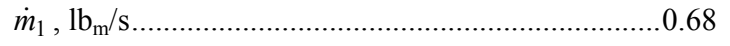 \\
\hline ....1.68 \\
\hline 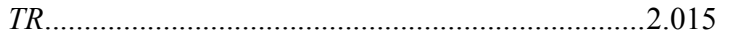 \\
\hline 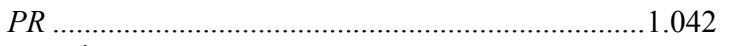 \\
\hline$P_{1}$, psia \\
\hline$T_{1}, \mathrm{R}$ \\
\hline$\delta_{\text {inlet }}$, in. \\
\hline 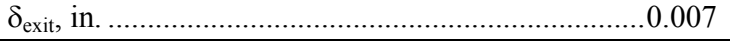 \\
\hline
\end{tabular}

The code was run to a limit cycle according to the procedure described in Section I. The wave diagram for this operating point is not shown, as it is quite similar to that of figure 5. The computed distributions of total and static pressure in Port 4 are shown compared to discrete experimental measurements in figure 7 . The relevant code output is labeled 'nominal' in the legend. All of the code data has been time averaged over the passage passing period, since this is what the experimental probes actually measure. The code results follow the trends in the measurements very well. Note for example the presence of the total pressure spike at approximately 0.3 radians across the port. This results from the residual reflected shock described in Section IV. The code correctly captures the primary, and more subtle secondary gasdynamic phenomena.

On the other hand, the code significantly over predicted both total pressures and static pressures. Using discrete code output to perform a mixing calculation similar to that done with the experimental results, an averaged $P R$ of 1.12 was obtained. This is $7.5 \%$ above the measured value shown in table 1 ; a significant disparity. The static pressure in Port 4 required to obtain the experimental mass flow rate was $11 \%$ above the average experimental value.

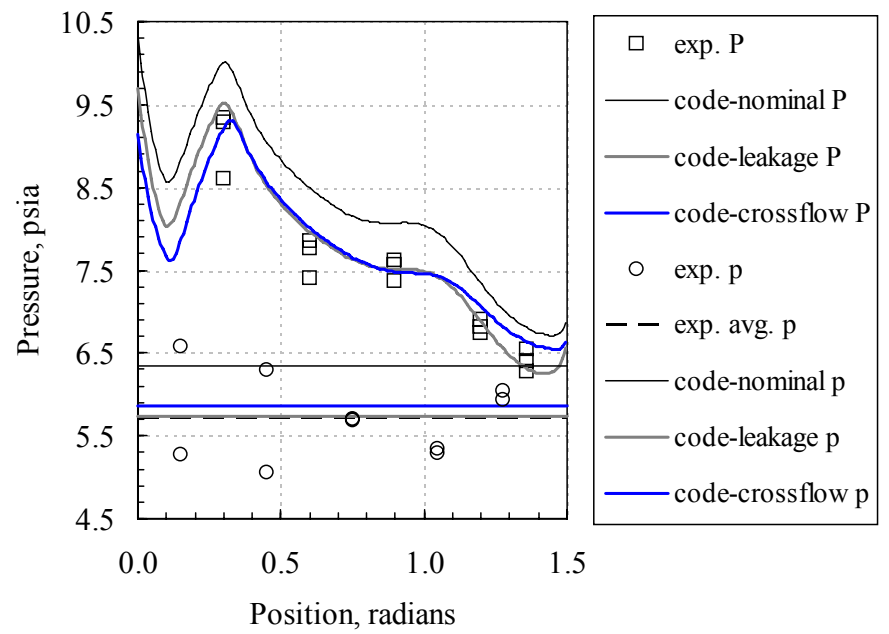

Figure 7.- Predicted and measured total and static pressures in Port 4 for the Case 1 operating point described in table 1. 
Nearly all of the loss mechanisms modeled in the code could be altered to account for these discrepancies. Gradual opening, viscous, and internal leakage losses all have the effect of impeding throughflow, thereby requiring a reduction in static back-pressure to achieve a given flow rate. The reduced static pressure and the entropy created by the losses will, in turn, lower the total pressure. However, the viscous and gradual opening loss models were calibrated using a wide variety of previous wave rotor experiments, and are general. Altering these models to fit the current experiment would have rendered them inappropriate for the previous experiments with no basis for the change. Furthermore, it was observed, but is not shown here, that tuning these models for this operating point would yield poor comparison at other operating points.

Internal leakage on the other hand, particularly that occurring at the exhaust end was a compelling explanation for the Port 4 discrepancies. There were difficulties in assembling the moveable endwall described in Section II, and it was not entirely clear that the setup functioned as envisioned. Clearances could not be inspected once the rotor was placed inside the housing, and no provision was made to measure them during operation (proximity probes were added to a later build). Furthermore, there was evidence of endwall movement during initial operations; however, a detailed discussion of such is beyond the scope of this paper. Lastly, the sealing of internal leakage has been a notably difficult task in past wave rotor research efforts.

In order to examine this explanation, the code was operated in a non-standard fashion. The experimentally measured average static pressure in Port 4 was imposed and the Port 1 mass flow was adjusted to match the measured value by varying the exhaust end clearance, $\delta_{\text {exit. }}$ Other parameters $(\lambda$, and $T R)$ were established as usual. The value of $\delta_{\text {exit }}$ required to achieve this condition was $0.034 \mathrm{in}$. This is approximately 5 times the nominal clearance value, but it is well within the realm of possibility, as the gap between the moveable and fixed endwalls was over $0.065 \mathrm{in}$. The Port 4 code output for this simulation is shown in figure 7 under the legend designation of 'leakage'. The match with experimental results is very good. The computed value of $P R$ is 1.05 , which is within $1 \%$ of the measured value.

Another potential internal leakage path was also considered and examined with the code. If the tab seals shown in figure 4 do not function properly (and there is no way to verify that they were), it is possible for high pressure gas in Port 2 to discharge into Port 4, as described in Section III. If this were to occur, the mass flow rate at the exit plane of the rotor in Port 2 would be greater than the value measured by a flow meter located some distance down the Port 2 duct. Correspondingly, the exit plane mass flow rate of Port 4 would be less than the flow rate measured downstream. Since flow rates are indeed measured downstream of the ports in the experiment, and since they are measured at the rotor exit plane by the code, this scenario can be examined with the code by forcing the flow from Port 4 to be less than Port 1 (by raising the imposed Port 4 static pressure). As a result, since the code is conservative, there will be more flow from Port 2 than into Port 3. Examination of figure 4 in the light of this potential leakage scenario implies that the measured static pressure in Port 4 would be less than the value at the rotor exit plane (i.e., the value imposed on the code). The disparity between the two would depend on the leakage rate. An estimate of the difference may be made using an incompressible momentum balance as follows

$$
p_{\text {4imposed }}=p_{4 \text { measured }}+\frac{\left(\dot{m}_{4} \dot{m}_{\text {leakage }}+\dot{m}_{\text {leakage }}^{2} / 2\right)}{\rho_{4} A_{4}^{2}}
$$

This equation was incorporated into the code, and the cross-port leakage was adjusted until the Port 1 mass flow matched the measured value and $p_{4 \text { measured }}$ was within $2 \%$ of the experimentally observed average. Other parameters of the operating point were again established as usual. The resulting Port 4 total pressure distribution is shown in figure 7 under the legend designation of 'crossflow'. It is virtually indistinguishable from the other leakage curve, and matches the data very well. The computed cross flow required for this result was approximately $14 \%$ of the inlet flow, or $0.098 \mathrm{lb} / \mathrm{s}$. This value is not unreasonable for the known gap and port dimensions if the tab seals failed to close. Thus, either leakage scenario described represents a plausible explanation for the disparity between measured and nominally computed wave rotor performance at this operating point.

As mentioned earlier, the early wave rotor rig data encompassed many measurements with which to compare the simulation code. These comparisons are presented in the next several figures, for the same operating point just described. 


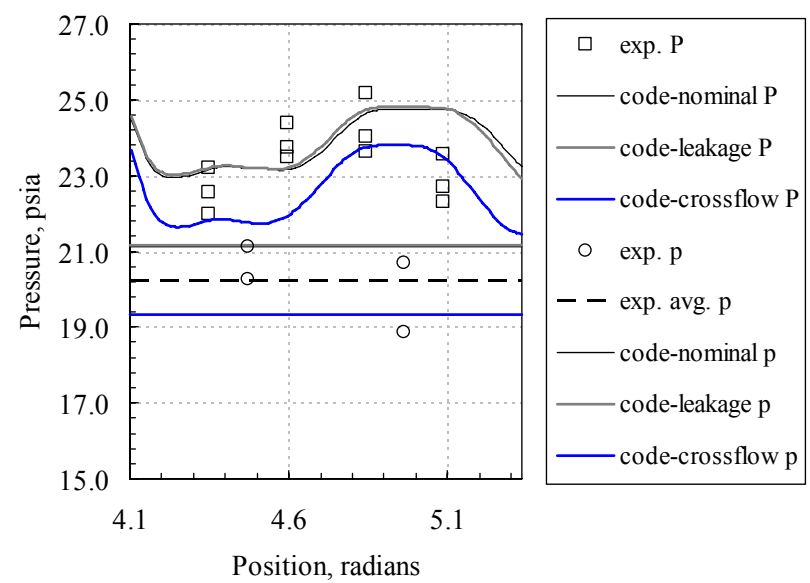

Figure 8.-Predicted and measured total and static pressures in Port 2 for the Case 1 operating point described in table 1.

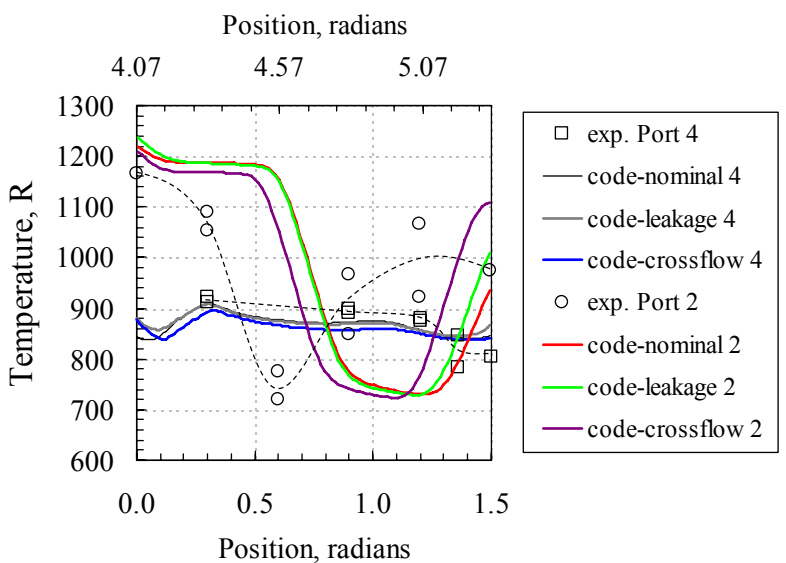

Figure 9.-Predicted and measured total temperatures in Ports 2 and 4 for the Case 1 operating point described in table 1.

Figure 8 shows the measured and computed total and static pressures for Port 2. As with figure 7, the results of the nominal and internal leakage scenarios are shown. All of the computed total pressure profiles track the measurements fairly well; although the measured data appears shifted toward the port leading edge relative to the computed results. The reason for this is unclear, although it should be kept in mind that experimental measurements are made several passage diameters downstream of the plane where the computational measurements are made. The mixing-averaged total pressures obtained from the code are all within 5\% of that obtained from the measurements. The computed static pressure values are with $3 \%$ of the measured average.

Measured and computed Total temperature distributions for Ports 2 and 4 are shown in figure 9. Crude curves have been drawn through the experimental data for clarity. These are shown as dashed lines. Considering first the Port 4 distributions, all of the computed results match the experimental values very well. Of course, the computed mass-averaged total temperatures match those of the experiment because that is a parametric requirement. However, the fact that the shapes of the various distributions match is encouraging. The measured drop in temperature at the trailing edge of the port is consistent with the internal leakage scenario described earlier (though other explanations are possible). Several components of the wave rotor (including the moveable endwall) are actively cooled by internal water channels. Any gas that passes over them will, in all likelihood be cooled as well. The gas leaking from Port 2 to Port 4 fits this description, and enters Port 4 at the trailing edge. This effect is not modeled in the code, and hence does not show in the computed results.

The computed and measured Port 2 temperatures follow the same trends, although the same leftward shift described in figure 8 is observed. Note too the substantial radial gradients in the trailing edge measurements. This indicates a highly three-dimensional flowfield, the details of which are impossible to consider with a onedimensional code. Remarkably though, the computed, mass-averaged temperatures matched the mass-average of the measurements to within $1 \%$.

As a final comparison for this initial test point, figure 10 shows measured and computed distributions of pressure on board the rotor over the course of one complete cycle. The upper plot represents a location approximately $0.95 \mathrm{in}$. downstream of the inlet end. The lower plot is approximately 0.95 in. upstream from the exhaust end. All of the computed results match the measurements with regard to profile shapes. As with the port flow comparisons, this implies that the speed and strength of the gasdynamic waves which govern the device are well predicted by the code. A closer inspection of the computed results indicates that either leakage scenario is better matched to the experimental results overall than the nominal computation. This is particularly evident in the regions away from the ports at either end of the rotor.

The inlet endwall pressures are also presented in figure 10 for reference. These would not be expected to precisely match the on-board measurements as they are at different axial locations and represent passage passing time-averaged, rather than instantaneous values (a passage width is 0.2 radians). Nevertheless, they should be close to the corresponding on-board readings, and plotting the two together lends confidence to the validity of observed circumferential gradients. 


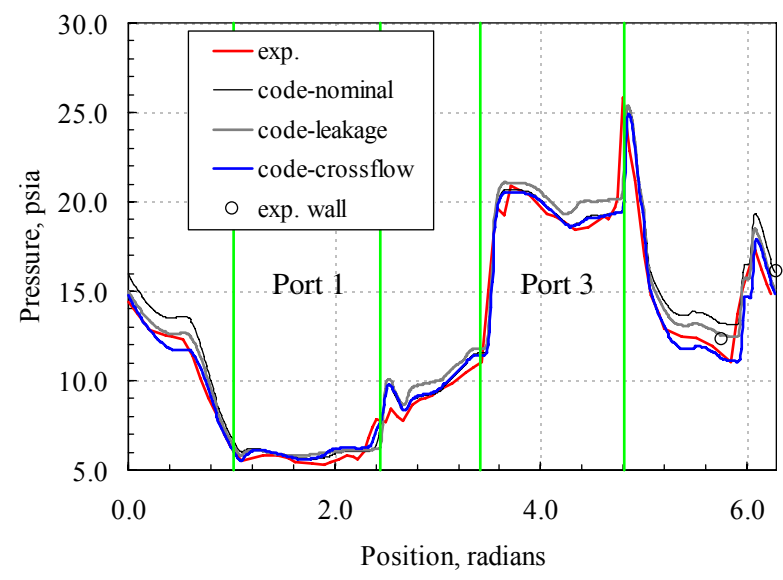

(a)

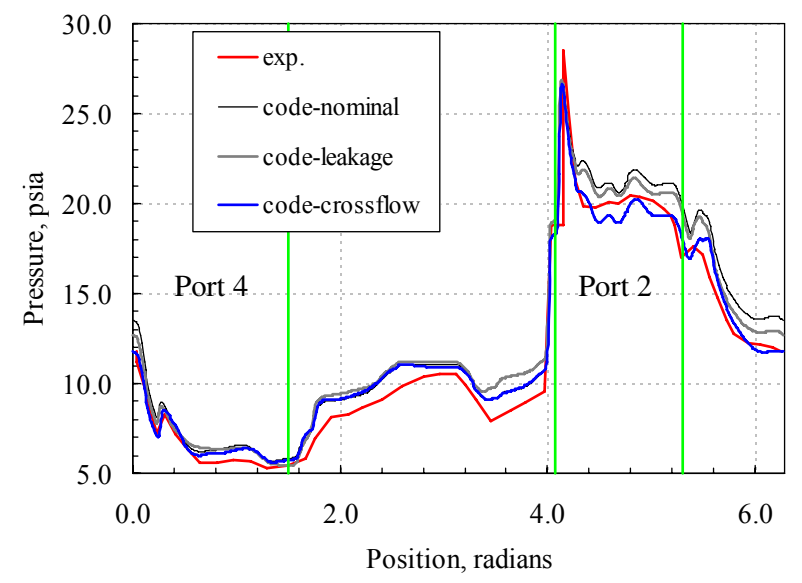

(b)

Figure 10.-_Predicted and measured static pressures on board the rotor (a) 0.95 in. downstream from the inlet end and (b) 0.95 in. upstream from the exhaust end during one cycle of the Case 1 operating point described in table 1.

\section{B. Case 2: Off-Design Point}

The second of the initial runs with which comparison will be made represents operation at the far left of the figure 6 engine operating line. The nominal operating parameters are listed in table 2 . At the time that the experimental data was collected, the dynamic pressure transducers on-board the rotor had become non-functional. Thus no comparison with the code is possible. The wave rotor demonstrated particularly poor performance compared to nominally computed expectations, and the cause was again attributed to internal leakage due to either unexpectedly large gaps, or non-functioning tab seals. As such, the nominal computed data will not be shown. Only the computed results assuming an exhaust-end leakage gap of $0.05 \mathrm{in}$. will be presented. In fact, the reason for presenting these experimental results at all is because they result in a unique internal flow field with which to validate the code.

TABLE 2.-RUN PARAMETERS

FOR INITIAL CASE 2

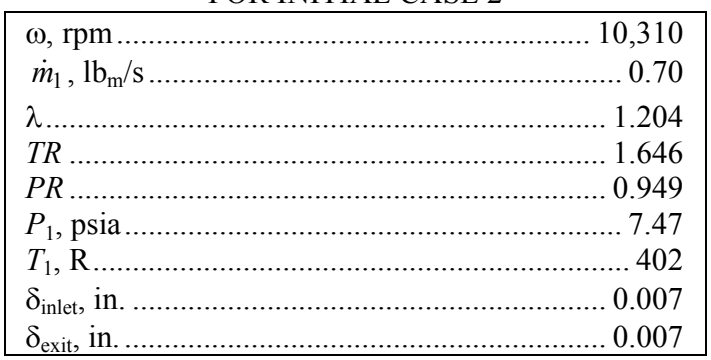

At this operating point, there is a large fraction of the flow entering Port 1 that does not exit to Port 2. It is instead trapped on board the rotor and exits through Port 4. In principle, this mass of relatively cold flow should be detected by the thermocouples near the leading edge of Port 4 . Figure 11 shows the experimentally measured and computed distributions of static pressure, total pressure, and total temperature in Port 4 for this operating point. Also shown in the lower right of the figure are the computed contours of temperature in order to clarify the flow path and wave processes. The predicted gradient is clearly evident in both the measured and computed results. It is noted parenthetically that the distributions of total pressure match well in magnitude and form. These results show that even at conditions far from the design point, the code captures not only wave dynamics but gross flow path characteristics as well. 

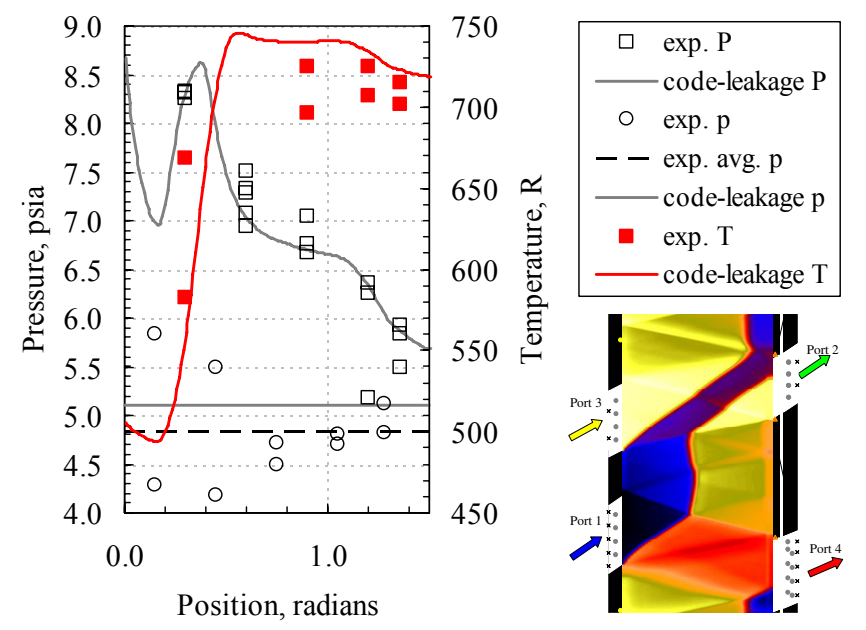

Figure 11.-Predicted and measured static pressures, total pressures, and total temperatures in Port 4 of the Case 2 operating point described in table 2.

\section{Recent Results: 2005-2006}

Based on the initial experimental and computational results, the wave rotor rig was substantially modified to prevent the suspected exhaust end leakage. New assembly procedures were also established to insure that the complex series of components comprising the moveable endwall assembly were installed as intended. The redesign resulted in the loss of some instrumentation capabilities; however, those essential to measuring performance, namely the port transducers, were retained, and in some cases augmented. Proximity probes were also installed to measure $\delta_{\text {exit }}$. The modifications proved worthwhile, as the performance improved substantially.

This section of the paper compares the simulation code to the most recent data collected from the rig. Comparison will be made based primarily on averaged port parameters such as mass averaged total pressure, and mixing-averaged total temperatures. It is reiterated that, to the degree possible, the same procedure is used in the code that is used in the experiment. This includes the use of computed data from discrete locations corresponding to those of the probes. It also includes the calculation of primitive variables such as velocity in the same manner as is done in the experiment even though these quantities are readily available directly from the code. This is done because it has been recognized that these factors can make a substantial difference in the resulting averages. Given that there is unsteadiness in the ports of time scales related to the passage passing period, a time averaged velocity for example will not necessarily be the same as a velocity calculated from the time averaged total and static pressures.

\section{A. Variation in $T R$ with Fixed Inlet Mass Flow Rate, Loop Flow Ratio, and Rotor Speed}

Computed and experimentally measured mixed pressure ratio as a function of mixed temperature ratio curves are compared in figure 12. The inlet flow rate, rotor speed, and loop flow ratio were held to the constant values listed in table 3. This type of plot is somewhat analogous to operating along the installed throttle line shown in figure 6, although in the actual case the loop flow ratio would not be constant. Simulated and measured performance are seen to agree quite well both qualitatively and quantitatively. The discrepancy at the lower temperature ratios may be due to the crossflow leakage path described earlier. The proximity probes did not show substantial movement of the moveable endwall relative to the rotor, so the alternative leakage path does not seem plausible. Even if crossflow leakage is responsible however, it has at least been substantially reduced from the initial runs. The amount of crossflow required to bring the computed and measured $P R$ values into line at $T R=1.6$ is approximately $2 \%$ of the Port 1 mass flow rate. This should be compared to rates in excess of $14 \%$ required to match the performance of the initial run data. If crossflow leakage can't explain the discrepancy, it should be borne in mind that it is small anyway. The maximum pressure ratio disparity is approximately $1 \%$ of the experimentally measured value. 


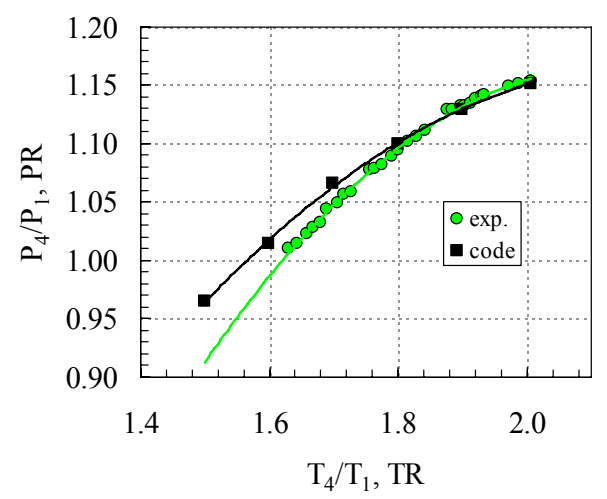

Figure 12.-Predicted and measured total pressure ratio as a function of total temperature ratio with fixed parameters described in table 3.

TABLE 3.-PARAMETERS FOR FIGURE 12.

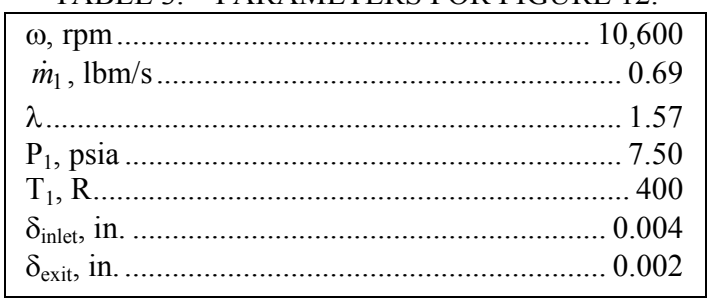

Figures 13 to 15 compare computed and experimentally measured probe data in Ports 2 and 4 for the operating point corresponding to the upper right point of figure 12. These are equivalent to figures 7 to 9 for the initial runs. As expected, the match between predictions and measurements is quite good, and no assumption of leakage is required. From these comparisons, and noting that the code was not 'tuned' for this wave rotor rig in any way, it may be concluded that the code is capable of accurately predicting four port wave rotor performance.

\section{B. Variation in Inlet Mass Flow with Fixed TR, Loop Flow Rate, and Rotor Speed}

In this comparison computed and experimentally measured pressure ratios were examined as functions $\dot{m}_{1}$ while $T R$, rotor speed, and loop flow rate (not ratio) were held to the constant values listed in table 4 . The results are presented in figure 16. Here it is seen that although the code results correctly predict the experimental trends, there is substantial disparity as the flow rate increases. Once again, the cause of the disparity is unknown for certain, but is consistent with crossflow in the vicinity of the tabs seals. Aligning the computed and measured pressure ratios at the highest measured inlet mass flow rate of $0.72 \mathrm{lb}_{\mathrm{m}} / \mathrm{s}$ requires crossflow at $9.7 \%$ of the inlet mass flow rate. This is still substantially less than earlier tests, but is considerably more than was required in the previous comparison. It is noted that the required Port 4 static pressure for this amount of crossflow is within $2 \%$ of the average measured value. 


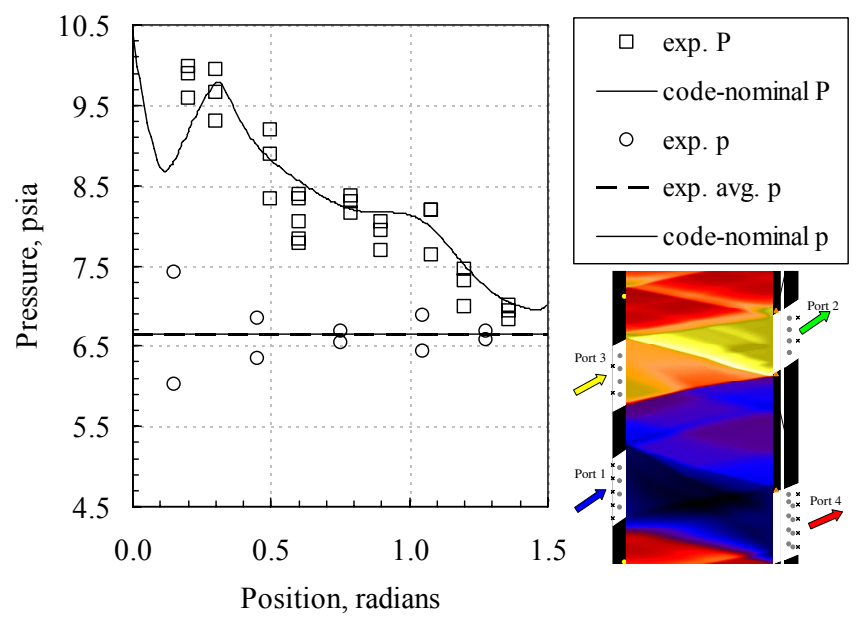

Figure 13.-Predicted and measured total and static pressures in Port 4 for the operating point described in table 3 , at $T R=2.0$.

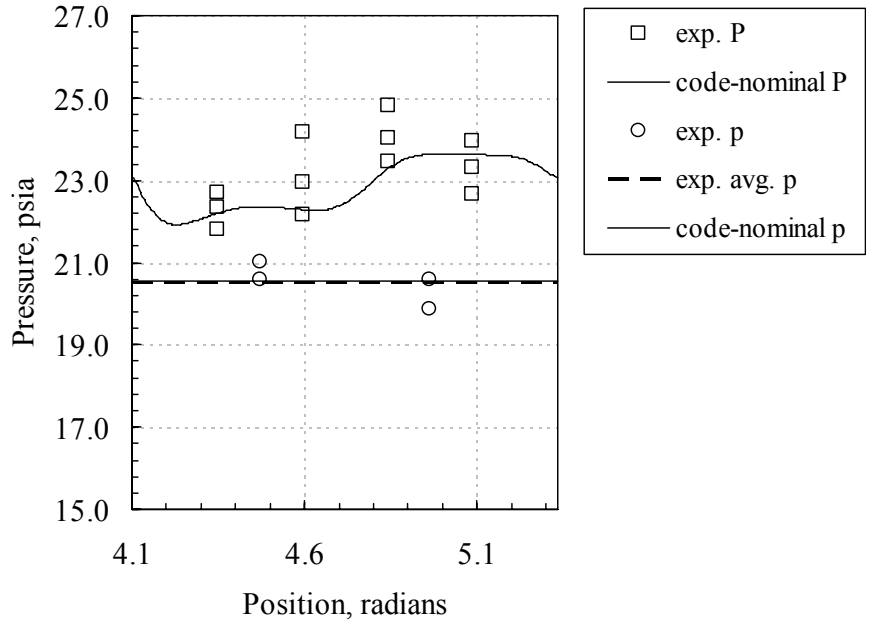

Figure 14.-Predicted and measured total and static pressures in Port 2 for the operating point described in table 3 , at $T R=2.0$.

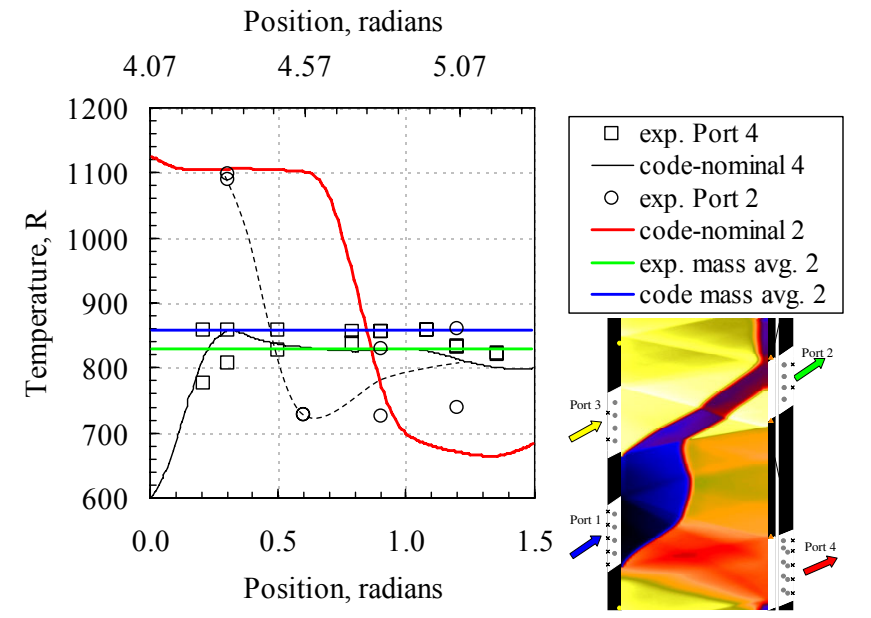

Figure 15.-Predicted and measured total temperatures in Ports 2 and 4 for the operating point described in table 3 , at $T R=2.0$. 


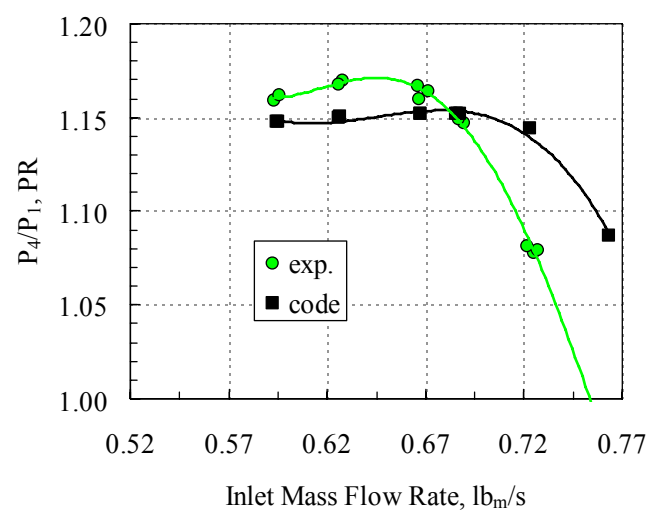

Figure 16.--Predicted and measured total pressure ratio in Port 4 as a function of inlet mass flow rate with fixed parameters described in table 4.

\section{TABLE 4.-PARAMETERS FOR FIGURE 16}

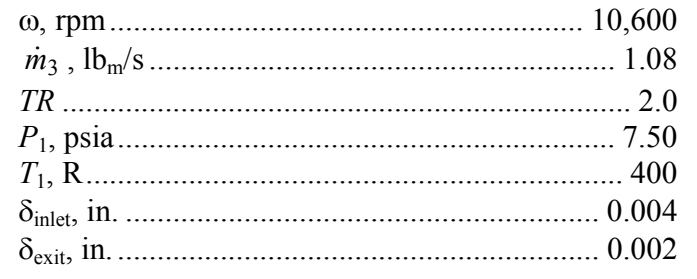

One difficulty with the crossflow explanation is that it does not occur at all test points. This implies, if crossflow is the reason for the performance degradation, that some aspect of the operating point must trigger it. In other words, the tab seals (or some internal leakage path) are opening due to some particular conditions. It is difficult to speculate on what these conditions might be, or what mechanism might be involved in the seal failure. It is noted however, that the best performance (i.e., least crossflow required in the simulation to match experiment) occurs at the highest temperatures in Port 2. This is true for initial and recent results. It is possible that something expands or warps at the higher temperatures and affects a better or complete seal.

\section{Variation in Rotor Speed with Fixed Inlet Mass Flow, TR, and Loop Flow Ratio}

In this final comparison of recent results, computed and experimentally measured pressure ratios were examined as functions of rotor speed while $\dot{m}_{1}, T R$, and $\lambda$ were held to the constant values listed in table 5 . The results are presented in figure 17. Here it is seen that the code correctly predicts the performance trend. There is a clear speed at which peak pressure ratio is observed. Quantitatively, the match is also quite good except at the lower speeds. The reason for the disparity is not clear at present, nor is the apparent rightward shift of the code-curve relative to the experimental results.

TABLE 5.-PARAMETERS FOR FIGURE 17

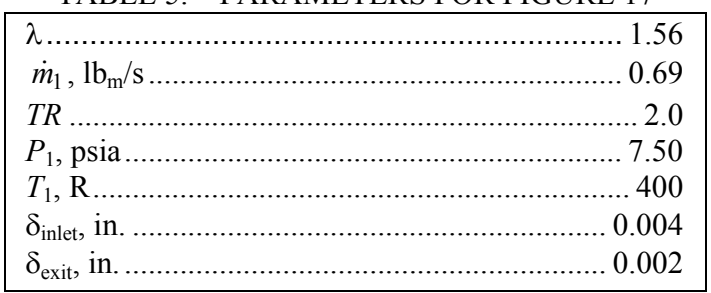




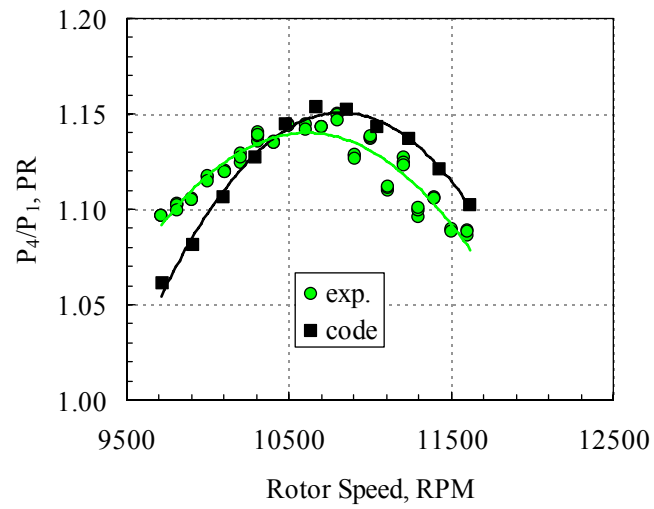

Figure 17.-Predicted and measured total pressure ratio in Port 4 as a function of rotor speed with fixed parameters described in table 5.

\section{Conclusion}

A one-dimensional, time-accurate, CFD-based wave rotor simulation code has been compared to experimental results from a four-port, through-flow style rig with which it was partially designed. Comparisons with measurements were made at both on and off design conditions. It was found that the gasdynamic phenomena which govern the wave rotor operation were well modeled by the code, and that global performance metrics such as output pressure ratio were well matched. At some operating points, the match with measurement required the supposition of unverifiable internal leakage. The internal leakage is plausible but not provable in the current experimental setup.

\section{References}

1. Wilson, J. and Paxson, D.E., "Wave Rotor Optimization for Gas Turbine Engine Topping Cycles," AIAA Journal of Propulsion and Power, vol. 12, no. 4, 1996, pp.778-785.

2. Welch, G.E., Jones, S.M., and Paxson, D.E., "Wave Rotor Enhanced Gas Turbine Engines," ASME Journal of Engineering for Gas Turbines and Power, vol. 119, 1997, pp. 469-477.

3. Wilson, J., Welch G.E., and Paxson, D.E., "Experimental Results of Performance Tests on a Four-Port Wave Rotor," AIAA Paper 2007-1250, January 2007.

4. Wilson, J., "Design of the NASA Lewis 4-Port Wave Rotor Experiment," AIAA Paper 97-3139, June 1997.

5. Welch, G.E., Slater, J.W., and Wilson, J., "Wave Rotor Transition Duct Experiment," AIAA Paper 2007-1249, January 2007.

6. Paxson, D.E., "Comparison Between Numerically Modeled and Experimentally Measured Wave Rotor Loss Mechanisms," Journal of Propulsion and Power, vol. 11, no. 5, 1995, pp. 908-914.

7. Paxson, D.E., "An Incidence Loss Model for Wave Rotors With Axially Aligned Passages," AIAA paper 983251, July 1998.

8. Paxson, D.E. And Wilson, J., "Recent Improvements to and Validation of the One Dimensional NASA Wave Rotor Model," NASA TM-106913, May 1995.

9. Paxson, D.E., "A General Numerical Model for Wave Rotor Analysis," NASA TM-105740, July 1992.

10. Paxson, D.E., "Numerical Simulation of Dynamic Wave Rotor Performance," AIAA Journal of Propulsion and Power, vol. 12, no. 5, 1996, pp. 949-957.

11. Foa, J.V., Elements of Flight Propulsion, John Wiley and Sons, 1983, pp. 163-165. 


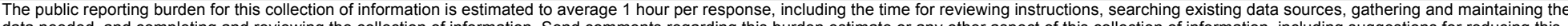

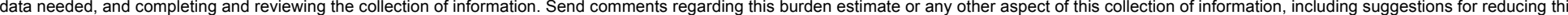

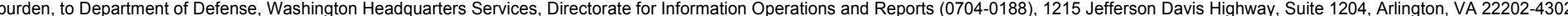

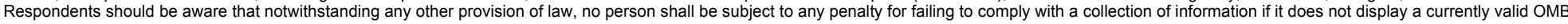
control number.

PLEASE DO NOT RETURN YOUR FORM TO THE ABOVE ADDRESS.

\section{REPORT DATE $(D D-M M-Y Y Y Y)$ \\ 2. REPORT TYPE \\ 3. DATES COVERED (From - To)}

01-10-2007

Technical Memorandum

\section{TITLE AND SUBTITLE}

Comparison Between Simulated and Experimentally Measured Performance of a Four Port

Wave Rotor

\section{5a. CONTRACT NUMBER}

5b. GRANT NUMBER

5c. PROGRAM ELEMENT NUMBER

\section{AUTHOR(S)}

Paxson, Daniel, E.; Wilson, Jack; Welch, Gerard, E.

\section{5d. PROJECT NUMBER}

5e. TASK NUMBER

5f. WORK UNIT NUMBER

WBS 561581.02.08.03.17.02

\section{PERFORMING ORGANIZATION NAME(S) AND ADDRESS(ES)}

National Aeronautics and Space Administration

\section{PERFORMING ORGANIZATION} REPORT NUMBER

John H. Glenn Research Center at Lewis Field

E-16166

Cleveland, Ohio 44135-3191

\section{SPONSORING/MONITORING AGENCY NAME(S) AND ADDRESS(ES)}

National Aeronautics and Space Administration

Washington, DC 20546-0001

and

U.S. Army Research Laboratory

Adelphi, Maryland 20783-1145

\section{DISTRIBUTION/AVAILABILITY STATEMENT}

Unclassified-Unlimited

Subject Category: 07

Available electronically at http://gltrs.grc.nasa.gov

This publication is available from the NASA Center for AeroSpace Information, 301-621-0390

\section{SUPPLEMENTARY NOTES}

\section{ABSTRACT}

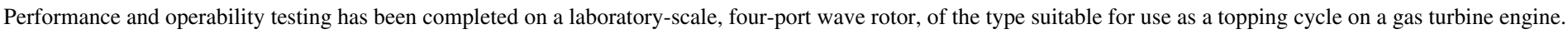

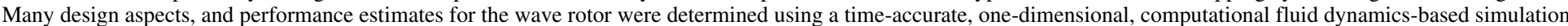

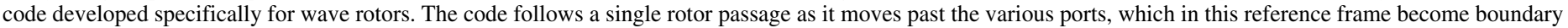

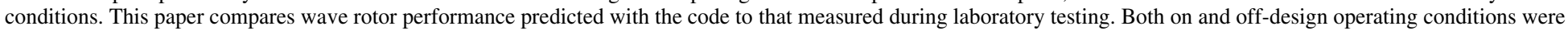

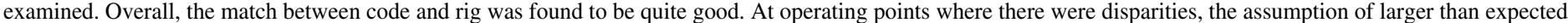
internal leakage rates successfully realigned code predictions and laboratory measurements. Possible mechanisms for such leakage rates are discussed.

15. SUBJECT TERMS

Wave rotors

\begin{tabular}{|c|c|c|c|}
\hline \multicolumn{3}{|c|}{ 16. SECURITY CLASSIFICATION OF: } & \multirow{2}{*}{$\begin{array}{l}\text { 17. LIMITATION OF } \\
\text { ABSTRACT } \\
\text { UU }\end{array}$} \\
\hline $\begin{array}{l}\text { a. REPORT } \\
\text { U }\end{array}$ & $\begin{array}{l}\text { b. ABSTRACT } \\
\text { U }\end{array}$ & $\begin{array}{l}\text { c. THIS } \\
\text { PAGE } \\
\text { U }\end{array}$ & \\
\hline
\end{tabular}

18. NUMBER
OF
PAGES
22

10. SPONSORING/MONITORS ACRONYM(S)

NASA; ARL; AIAA

11. SPONSORING/MONITORING REPORT NUMBER

NASA/TM-2007-214985; ARL-TR-4202;

AIAA-2007-5049 

